\title{
Computer Assisted Knee Replacement Surgery: Is the Movement Mainstream?
}

Frederic Picard $^{1,2^{*}}$, Jon Clarke ${ }^{1,2}$, Kamal Deep $^{1}$ and Alberto Gregori ${ }^{3}$

${ }^{1}$ Golden Jubilee National Hospital, University Glasgow, UK

${ }^{2}$ Bioengineering Department Strathclyde University Glasgow, UK

${ }^{3}$ Hairmyres Hospital, UK

"Corresponding author: Frederic Picard, Orthopaedic Consultant, Bioengineering Department Strathclyde University, Golden Jubilee National Hospital, Agamemnon Street Clydebank Glasgow, G81 4 DY, UK, Tel: +00441419515564; E-mail: frederic.picard@gjnh.scot.nhs.uk

Received date: Mar 29, 2014, Accepted date: June 09, 2014, Published date: June 15, 2014

Copyright: (c) 2014 Picard F, et al. This is an open-access article distributed under the terms of the Creative Commons Attribution License, which permits unrestricted use, distribution, and reproduction in any medium, provided the original author and source are credited.

\begin{abstract}
The first computer-assisted Total Knee Arthroplasty (TKA) was performed in 1997. The FDA approved computer assisted knee arthroplasty systems used in the early 2000s. Since then, surgeons and institutions all over the world have gradually adopted the technology. While the computer holds an importance place in the majority of workspaces across all industries, computer-assisted surgical technique has yet to become the preferred tool of the orthopaedic surgeon. Why has "e-instrumentation" not yet substituted conventional instrumentation in TKA orthopaedic surgery?

In this article, we argue that main reasons which oppose the use of this technology are based on inaccurate or misleading observations. We isolated the factors likely to explain such opposition to this innovation: current results of total knee replacement, surgeon age, operative time, system ergonomics, cost for users, and cost for suppliers and "disruptive" innovations. Other factors such as surgeon habits, hospital environment and available assistance for support, although relevant, are not discussed. We assessed the advantages and drawbacks, costs and benefits of this technology to assess whether or not this opposition is justified. Finally, we explored the reasons why such a technology may impel surgeons to use this technique or any "related technologies" in the future.

The main factors limiting TKA navigation spreading amongst orthopaedic surgeons are ergonomics and economics. Other factors, such as current TKA outcomes and surgeon's age are fallacious arguments in the rebuttal of CAS system use. Computer assisted knee arthroplasty surgery is not yet mainstream, but TKA will not escape technological progress.
\end{abstract}

Keywords: Total knee arthroplasty; Arthroplasty; Orthopaedic surgeons; computer-assisted knee arthroplasty

\section{Introduction}

The first total knee arthroplasty (TKA) which was computerassisted navigated was performed in 1997 [1]. At the beginning of the 21 st century the first computer-assisted knee arthroplasty systems were FDA approved [2]. Since then, the technology has gradually begun to be used more frequently around the world. Other than Germany, where more than 30\% of orthopedic surgeons use computer-assisted technology in knee arthroplasty - possibly due to the premature introduction of computer-assisted techniques in the 1990s such as the Robodoc ${ }^{\circledast}$ system - many countries have yet to adopt this technology in daily surgical practice [3]. In the United Kingdom and the USA, this figure is less than 3\% [4-6]. In Australia, the 2013 Registry collected data on 42,584 knee replacement procedures undertaken for osteoarthritis which used computer navigation [7]. In emerging countries such as Brazil [8], private institutions have been interested in the marketing aspect of this technology as it could potentially attract increasingly wealthier clientele. No more than $6 \%$ of practicing surgeons use navigation in knee arthroplasty in France [9]. The numbers are unclear in Asian countries such as China and Korea, even though there is obvious interest for the technology [10]. CT Free computer-assisted surgery was also approved and commercialized as late as 2006 by the Ministry of Health, Labor and Welfare in Japan [11]!

While the computer has taken over a large proportion of workspaces everywhere even up to operative areas such as the anaesthetist's and theatre staff's workspaces, the computer-assisted surgical technique has yet to become the favored or preferred tool of the orthopaedic surgeon. Why has "e-instrumentation" not yet substituted conventional instrumentation in TKA orthopaedic surgery? The reasons this system has not yet entered the mainstream are largely highlighted by an article reporting the results of a webbased survey comprising of 24 questions relating to computer-assisted surgery. The questionnaire was sent to 3330 members of the European Society of Sports Traumatology Knee Surgery and Arthroscopy (ESSKA) and the Swiss Orthopedic Society (SGO-SSO). Of the 389 members who replied, $202(51.9 \%)$ said that their centres were equipped with navigation systems, of which $124(61.4 \%)$ use it for TKA. Regarding the frequency of use of CAOS, 102 (50.5\%) use it in less than $25 \%$ of cases, while $52(25.7 \%)$ use it in more than $75 \%$ of cases.

Of those whose centres equipped with navigation systems, 102 (50.5\%) considered navigation "a real innovation contributing to improvement of total knee implantation", yet the most strongly cited reason for not using a navigation system was the potential for increasing operation times and the risk of infections. Half indicated they considered the system a real innovation and $48 \%$ estimated they 
would be able to use these systems more frequently in the future. Those who were frequent users of CAOS said they used it mostly routinely. Finally, the principal reported reason for using these systems was the desire to improve alignment of TKA implants. However, those who did not wish to use navigation systems were concerned about potential increased risk of infection, as a result of supplemental screw or pin use compared to the conventional method along with an increase in operation time [12]. To what extent are these concerns justifiable?

In this article, I argue that most of the reasons to oppose this technology are based on unjustified observations. I will isolate the factors likely to explain the opposition to this innovation. Studies by Friederich et al. 2008 amongst others demonstrate that these main factors include current results of total knee replacement, surgeon age, operative time, ergonomics of systems, cost for users, cost for suppliers and "disruptive" innovations [13]. Other potential contributing factors such as surgeon habits, hospital environment, available assistance for support, although relevant, are not discussed. I will assess the advantages and drawbacks, costs and benefits of this technology to assess whether or not these oppositions are justified. Finally, I will explore the reasons why such a technology may impel surgeons to use this technique or one of its "lineage technologies" in the future in some form or another.

\section{Current Results}

Knee arthroplasty is a very successful operation [14]. Indeed, results are considered highly acceptable as far as mean survival of implants and patient satisfaction is concerned [15]. Most orthopaedic surgeons are comforted by these statistics and subsequently do not foresee the need to change it.

However, scrutiny of TKA literature indicates a conflicting viewpoint and raises the question: is there is any room for improvement? In a cohort of 9700 papers extracted by Medline with "total knee replacement" as keywords, 30\% of the papers studied complications, $20 \%$ pain, $14 \%$ infections, $6 \%$ alignment, $5 \%$ rotational problems and $6 \%$ functional results. The early days of prosthetic surgery measured success with respect to pain, then mobility, and now attention has turned to the function expected by patients. Although the results on pain and range of motion are generally satisfactory, recent publications give an account of non-optimal functional results between $15 \%$ and $34 \%$ of patients after TKA [16-18].

We can evidently not be satisfied with such results in view of the growing proportion of functionally demanding and younger patients. It is estimated that $50 \%$ of TKA patients will be less than 65 years of age in the very near future [19]. Navigation is one of the factors that can lead to improved functional outcomes as shown by Choong et al. [20]. On the other hand, it is not known whether computer assisted surgery will be able to improve the current performance of TKA in terms of life expectancy and quality of life, although a recent article has shown that its usage decreased the number of cardiac accidents, without reducing other complications including the number of deaths $[21,22]$.

Let us look at another more practical aspect of TKA surgery; it is widely acknowledged that poor alignment of total knee prostheses represents a negative factor with respect to function and longevity of knee implants [23]. The question concerning the tolerable limits of acceptable alignment remains debatable $[24,25]$ but it is clear that beyond certain limits of femorotibial mechanical alignment, considered around $3^{\circ}$ by most authors, there is an increased risk of premature TKA failure [26]. Navigation has indisputably demonstrated an improvement in alignment of TKA components $[27,28]$.

Twenty-nine studies of CAS versus conventional TKA were identified, and included mechanical axis malalignment of greater than $3^{\circ}$ occurred in $9.0 \%$ of CAS vs. $31.8 \%$ of conventional TKA patients [29]. The risk of greater than $3^{\circ}$ malalignment was significantly less with CAS than conventional techniques for the mechanical axis, the frontal plane femoral, and tibial component alignment. These numbers seem to be trifling, but let us apply these differences in performance to the aviation industry. If we approximate the difference between the two techniques of conventional and navigation TKA as $20 \%$ and we apply this percentage to the number of daily flight in the world, we calculate that of about 100,000 flights per day 20,000 of those planes would land in the wrong location!

Today, patients are very demanding with regards to their knee function and an increasing number of them aspire to return to an athletic activity. Nilsdotter et al. [17] has shown that $41 \%$ of patients operated for TKA hoped to restore physical activity such as golf and dance, and only $14 \%$ were able to do so. We are dealing with a changing population of patients who desire a "normal" knee rather than one that is merely painless or suitably functioning. Navigation may help to maximize current TKA outcome to optimal range, although it might be beyond the realms of current TKA implants to give a normal knee back to patients.

When considering TKA outcomes several factors have to be analyzed. The literature shed light on the following aspects:

\section{Risks and Complications}

An article by Siston awarded by both AS and ISB Societies reviewed the current literature and found no increased risk in complications in TKA navigation compared to conventional surgery [30]. In fact, other articles seem to suggest that there may be less complications with navigation than with conventional surgery. For example, the number of systemic embolism, blood loss and the number of cardiac incidents seem to be reduced by navigation $[31,32]$. At the very least navigation does not appear to increase surgical complications, including the number of infections.

\section{Coronal and Sagittal Alignment}

As previously alluded to, ideal leg alignment after TKA remains a debate. What is the correct alignment for knee prosthesis? What are the acceptable limits not to surpass in order to avoid compromising the function and longevity of the prosthesis? [15] These two questions remain an ongoing concern but we can nevertheless confirm that navigation provides the tools to accurately and reliably quantify alignment during TKA surgery.

\section{Rotation Alignment}

Navigation has yet shown definite benefits with respect to this alignment parameter, although some authors such has Stockl et al. in 2004 have shown that femoral rotation may be improved with navigation. Others have highlighted the difficulty of finding anatomical landmarks used to orient the femoral implant, whereas Siston has suggested that the use of combined landmarks to adjust tibial and femoral rotation may be the best solution $[33,34]$. 


\section{Soft Tissue Balancing}

Since the 1970s, TKA soft tissue balancing techniques developed by Freeman and Insall have evolved through multiple phases of development. Navigation offers a remarkably precise, repeatable instrument to measure and evaluate the gaps in flexion and extension during a surgical procedure. Indeed, since the beginning of the $21^{\text {st }}$ century, gap management navigation software has been utilized and shown real benefit in soft tissue management [35].

\section{Functional Results}

We have already discussed this subject above and highlighted several articles that demonstrate the advantages of navigation with respect to knee function $[20,36]$. Therefore, among these factors which are considered as very important to TKA surgery, navigation favorably responds to surgeons' and patients' expectations. However, futher and more recent studies have yet to confirm this statement.

\section{Surgeon Age}

In most countries that provide this data, the mean age of orthopaedic surgeons is between 45 and 50 years old [37]. These surgeons graduated in the 1990s before the widespread use of the World Wide Web, and as a result may not have familiarized themselves with this kind of technology until much later on. In contrast, the younger generation has grown up with this technology and is therefore more likely to find the CAS systems appealing.

An excellent synthesis article by George Geddes refers to issues linked to the learning of computer technology by adults, and particularly by those who are older [38]. The author recalls that older adults can learn new techniques just as effectively as younger adults but generally require more practice. It is thus learning and education that are the most important elements in the introduction of computers to seniors.

Another study by Frieberg on the same subject has suggested that aduts aged 55 to 59 years old can reduce the probability of retiring earlier by regularly using computers [39]. Extrapolating these results to the field of orthopaedic surgery where the computer is a central element of computer assisted surgery, could suggest that age would not be an issue for senior surgeons working with computers [40]. There are nevertheless no studies looking at the correlation between the age of a user and their capacity to use navigation systems. A more recent study suggests that after only five days of computer usage, the same neural circuitry used by experienced users in the front part of the brain becomes active in computer internet naïve subjects as well [41].

\section{Operation Time}

For primary TKA, typical operative times are between 45 and 120 minutes [30]. Logically, high volume centres have the lowest duration time and perform more patients per list $[42,43]$. Understandably, surgeons working within such a structured system may be less inclined to change to a system that increases operation time. It clearly represents a limiting factor in the adoption of these techniques. Bauwens et al. demonstrated that it has been increased by $23 \%$ in his meta-analysis of 33 studies (11 RCTs) including 3423 patients [28].

Siston showed in his review that additional time with navigation was between 10 and 20 minutes, and more recently Smith et al. showed that approximately 20 navigated cases were required to match the operative time of a more experienced navigation surgeon. Ten extra minutes does not seem excessive in theory, in view of the benefit that it can bring to the patient [44]. On the other hand, 10 extra minutes per patient represents, after 6 patients, the time for another knee replacement.

This clearly represents a limiting factor in the adoption of these techniques.

\section{Ergonomics}

Fukushima, one of the pioneers in computer-assisted surgery in the field of neurosurgery, wrote about the subject: "Too much information, even sensible, can generate confusion and disorientation." Other industries have extensively studied the ergonomics of their respective technology to conclude, in part, that complexity of user interfaces does not necessarily improve users' adhesion to the products. In surgical fields other than orthopaedics, such as laparoscopy, evidence relating to the ergonomics of instruments has shown that the design of the instrument directly influences the frequency of its use. A designer reaches optimality for their design, as Antoine de Saint-Exupéry described it, "not when there is nothing left to add, but when there is nothing left to take away". Conventional instrumentation has probably reached the peak of user friendliness that most of the surgeons desired and it is with no surprise that the majority of them are satisfied and comfortable with it.

Ergonomics is an important factor in resistance to navigation technology, chiefly related to lack of system "user-friendliness" making the surgical procedure longer and more complicated. Instrument ergonomics has been studied for a long time in the field of surgery. In 1993 Lewis et al. showed that ergonomically-designed handles enabled higher working efficiency than existing handles [45]. New ergonomic requirements were created with the introduction of laparoscopic surgery [46]. Berger showed that laparoscopic instruments suffered from ergonomically inadequate handle designs and inefficient handleto-tip force transmissions, which lead to surgeon fatigue, discomfort, and hand paresthesias. The author concluded that improvements in the design of laparoscopic instruments were needed to decrease the work and discomfort of tissue manipulation during video-endoscopic surgery [47]. Computer-assisted surgery is facing similar challenges today that laparoscopic surgery tackled a few years ago.

\section{Cost for Users}

The cost of prosthetic knee surgery has become a major societal problem [48]. In fact, material costs and related payments such as blood products, hospitalization, rehabilitaton and implants represent huge costs supported by "paying authorities". Today, the cost of equipment is carried out by hospitals and orthopaedic companies which are ultimately charging the patients or intermediary payers such as insurance companies. For instance, conventional instrumentation utilized for joint replacements are neat sets of jigs (between four and ten boxes) that need to be sterilized and maintained after each operation at a very high cost. Most of the time, orthopaedic companies have to support the cost of the maintenance. Implants are becoming commodity items reducing the margin of orthopaedic companies who are trying to reduce their extra cost such as maintenance of inventory.

Pressures carried out by payers in the field of health care are all oriented towards the same direction of cost reduction in management. Health costs are astronomical; per annum, one person costs $\$ 6096$ in the United States, \$4000 in Switzerland, and a mean of \$2193 in all 
other countries including Japan [49]. In 1998, Tucker Consulting had already demonstrated that health institutions implicated in the payment of surgical interventions wanted to significantly reduce all the direct and indirect charges around arthroplasty, from the cost of prostheses to the time of hospitalisation. On the other hand, the pressures carried out on the rapidity with which surgeons and hospitals take charge of patients, increase the risks of problems. In fact, all increase of complications has a direct consequence on insurance charges that are directly reflected in patients' bills. Whether paid by the patients themselves or by national or private insurances, costs are increasing in an incontrollable manner and impact on surgical care. It is obvious that everyone including hospitals, payers, surgeons and orthopaedic companies are all trying to bring the cost down.

The cost of navigation equipment represents only a moderate price compared to the costs of implants. The purchase of a system does not really represent a major obstacle, especially if it is used daily. Indeed, for a surgeon or an institution that performs 200 knees per year, a $\$ 120 \mathrm{k}$ navigation system would cost $\$ 600$ per knee while the implants would cost 10 times more. No one would, for instance, argue against buying arthroscopic equipment nowadays for the reason that surgery can be performed by opening the joint. However, does navigation allow similar benefits to TKA surgery that arthroscopy does for knee ligamentoplasty?

In most countries, surgeons are not paid more if they use CAS systems and it takes longer to do the surgical procedure which can potentially affect over all orthopaedic surgeons and hospital revenues [6].

Novak, and others have all shown similar results: navigation can potentially reduce the costs of TKA in the long term, due to potential reduction of revisions [50,51]. A hidden Markov model (HMM) is a statistical model in which the system being modeled is assumed to be a Markov process with unobserved state. Computer-assisted surgery is both more effective and more expensive than mechanical alignment systems. Given an additional cost of $\$ 1500$ per operation, a $14 \%$ improvement in coronal alignment precision (within $3^{\circ}$ of neutral mechanical axis), and an eleven fold increase in revision rates at fifteen years with coronal misalignment (54\% compared with $4.7 \%$ ), the incremental cost of using computer-assisted surgery is $\$ 45,554$ per quality-adjusted life-year gained. Cost-savings is achieved if the added cost of computer-assisted surgery is $\$ 629$ or less per operation. Variability in published clinical outcomes, however, introduces uncertainty in determining the cost-effectiveness. However, these models have to be confirmed in the long run.

\section{Cost for Suppliers}

Half the world market of orthopaedics is in the USA, $12 \%$ is Germany, $10 \%$ for the rest of Europe, $10 \%$ for Japan and 22\% for the rest of the world. The highest-earning corporations for orthopaedic material are American and predominate the entire global market. These giants, Stryker, Zimmer, J\&J, Smith and Nephrew, and Biomet are strongly established all over the world with historical records, compelling portfolio devices and authoritative credibility. Suppliers are squeezed between more demanding shareholders and marginal reduction in product sales.

The big orthopaedic corporations do not push the utilisation of these systems because there are still added costs (systems for trials, representative for each case) with no substantial increase of incomes (same number of implants and possibly even less due to additionl time per case). These are the main economic reasons for the major orthopaedic companies preventing CAS from spreading and at the same time promoting other techniques such as custom jigs which are more cost neutral for them.

If we now match these orthopaedic corporations with corporations that produce and sell navigation equipment, we realise that apart from perhaps Stryker, the other orthopaedic majors are not extensively implicated in navigation. In addition, if these corporations really wanted to force the market to use navigation, it would cost them considerable investments to provide systems to surgeons who are still hesitant to buy them. Furthermore, in order to ensure proper servicing of these systems, a representative from the firm would have to be present with the surgeon through each intervention, at least at the beginning.

The literature has suggested that at least 20 knees have to be performed by a surgeon before achieving confidence with the machine43. Knowing that 3.7 TKA for generalist surgeons and 8.9 TKA for lower limb specialists are mean monthly figures in the USA, the biggest market in the world, it means a surgeon may require three and six months to be fully operational which represent a significant financial effort from suppliers [52]. Low volume surgeons are doing less than ten or fewer TKA whereas high volume surgeon is performing more than 50 a year [53]. This factor is certainly one of the most important elements in the lack of motivation for these corporations to promote navigation. In summary, navigation represents additional costs related to computers and supporting staff but with no additional income from the implants.

\section{Disruptive Innovations}

Christensen at the Harvard Business School has described a phenomenon he called "disruptive innovation" affecting any fields of technological products or companies. Indeed any technology even very successful could be stricken by disruptive process that disrupts a product or a company [54]. In contrast a "sustaining technology" is a continual technological evolution that allows a technique to be improved along the years and to attract an increasing number of adherents. The adoption of this technology is always done in the same way, firstly through innovators (the "enthusiastic"), then the pragmatics and finally the sceptics. A variable amount of time goes by between the first and last group, usually long in competent fields such as medicine and more rapid in more consumable technology. It took more than 40 years for conventional instrumentation in orthopaedics to mature and reach its current reliability.

Computer-assisted surgery for TKA took approximately 15 years to go from the first step, so called innovators category, to the second, so called early adopters category in countries like Germany. At times, the spreading time of certain technology is so long that it is overcome by another technology. This concept is called "disruptive innovation". For example, the computer represents a disruptive innovation compared to perforated cards that were increasingly used for similar tasks in the 1970s and 1980s. Most often, these disruptive innovations are pushed forward by a corporation in order to make a breakthrough or consolidate a market.

In the field of CAOS, the computer is more or less an electronic instrumentation adapted to the conventional instrumentation method to execute TKA, and therefore represents in this sense a "continuous" evolution compared to the conventional method. Even though this technology can be considered "discontinuous" or maybe "disruptive" 
Page 5 of 6

compared to conventional instrumentation, navigation consists only in tracking devices affixed on conventional tools.

What are these technologies or techniques labeled as "discontinuous" in orthopaedics? Two recent examples are part of this category: minimally invasive surgery and custom guides, also referred to as patient-specific instrumentation. Indeed, minimally invasive surgery, although not new (Judet described minimally invasive approach of the hip in the 1960s! [55]) has been massively popularized by several American orthopaedic companies. Thus, the focus of surgeons that was turned towards surgical navigation shifted to a technique more accessible to the majority of surgeons. It is simpler for a surgeon to understand a surgical mini-incision that solely concerns anatomy than to understand computers and their often complicated user interfaces. It has given birth to new surgical instrumentations adapted to minimally invasive surgery.

Patient specific instrumentation or jigs facilitate bone resections using prefabricated guides based on three dimensional reconstructions from MRI or CTs of the knee. They are easy to use and are theoretically fulfilling the requirements for knee alignment. This appealing concept for orthopaedic companies (externalization of services such as preop. images, reconstruction, planning, jigs designs) and for surgeons (few precalibrated jigs and preordered implants) gained popularity amongst orthopaedic community.

We can therefore see that "disruptive innovations" will create a technical discontinuity in the surgical practice, whereas a technology such as the one used in navigation, although following a normal and logical evolution of traditional equipment, will have more difficulty infiltrating itself into routine practice. Consequently, a sustaining technology has paradoxically more difficulties in imposing itself than a disruptive technology. The goals of those that promote the so-called "disruptive" techniques and technologies are evidently and logically mercantile and arise from the need to take new parts of the market, or to avoid losing any.

\section{Conclusion}

We have explored the factors limiting TKA navigation spreading amongst orthopaedist surgeons and identified the most restraining ones. The main factors are ergonomics and economics, and certainly also company driven or we should say restrained. Other factors, such as current TKA outcomes and age are fallacious arguments in the rebuttal of CAS system utilisation. Nevertheless, we can explain the reasons behind slow propagation of this technology. Computerassisted knee arthroplasty surgery is not yet mainstream, but TKA won't escape technological progress. Mahatma Gandhi said: "First they ignore you, then they laugh at you, then they fight you, then you win!" Therefore whatever we think, whatever we do, whatever we hear, computers may be in the orthopaedic operating room for routine knee replacement tomorrow or after tomorrow but they will be there!

\section{References}

1. Delp SL, Stulberg SD, Davies B, Picard F, Leitner F (1998) Computer assisted knee replacement. Clin Orthop Relat Res : 49-56.

2. Lavernia c, Hernandez VH, Hommen JP (2007) Cost Analysis of navigation in JB Stiehl, DiGioia, Anthony M., Rolf G. Haaker, and Werner H. Konermann, eds. Navigation and MIS in orthopedic surgery. Springer.

3. Desai, Aravind S, Asterios Dramis, Daniel Kendoff, and Tim N (2011) "Critical review of the current practice for computer-assisted navigation in total knee replacement surgery: cost-effectiveness and clinical outcome." Current reviews in musculoskeletal medicine 4: 11-15.

4. National Joint Registry for England, Wales and Northern Ireland | 10th Annual Report

5. Slover JD, Tosteson AN, Bozic KJ, Rubash HE, Malchau H (2008) Impact of hospital volume on the economic value of computer navigation for total knee replacement. J Bone Joint Surg Am 90: 1492-1500.

6. Conditt MA, Bargar WL, Cobb JP, Dorr LD, Lonner JH (2013) Current concepts in robotics for the treatment of joint disease. Adv Orthop 2013: 948360.

\section{Australian registry}

8. Albuquerque, Roberto Freire da Mota, Fbio Jansen Angelini, Jos Ricardo Pcora, Marco Martins Amatuzzi, et al. (2006) "Computer-assisted knee total arthroplasty." Acta Ortopdica Brasileira 14: 199-202.

9. Nizard R (2004) "Presentation des systemes de chirurgie assistee par ordinateur pour lâ $€^{\text {Tw }}$ orthopedie: navigation ou robotique? Avec ou sans imagerie." Journal de Radiologie 85: 1411.

10. Bae DK, Song SJ (2011) Computer assisted navigation in knee arthroplasty. Clin Orthop Surg 3: 259-267.

11. Ministry of Health, Labor and Welfare of Japan.

12. Friederich N, Verdonk R (2008) The use of computer-assisted orthopedic surgery for total knee replacement in daily practice: a survey among ESSKA/SGO-SSO members. Knee Surg Sports Traumatol Arthrosc 16: 536-543.

13. Craven, Michael P, Shirley M. Davey, and Jennifer L. Martin (2005) "Factors influencing wider acceptance of Computer Assisted Orthopaedic Surgery (CAOS) technologies for total joint arthroplasty."

14. Moran CG, Horton TC (2000) Total knee replacement: the joint of the decade. A successful operation, for which there's a large unmet need. BMJ 320: 820 .

15. Sharkey PF, Hozack WJ, Rothman RH, Shastri S, Jacoby SM (2002) Insall Award paper. Why are total knee arthroplasties failing today? Clin Orthop Relat Res : 7-13.

16. Noble, Philip C, Michael A. Conditt, Karon F. Cook, and Kenneth B. Mathis (2006). "The John Insall Award: Patient expectations affect satisfaction with total knee arthroplasty." Clinical orthopaedics and related research 452: 35-43.

17. Nilsdotter AK, Toksvig-Larsen S, Roos EM (2009) Knee arthroplasty: are patients' expectations fulfilled? A prospective study of pain and function in 102 patients with 5-year follow-up. Acta Orthop 80: 55-61.

18. Beverland D (2010) Patient satisfaction following TKA: Bless them all! Orthopedics 33: 657.

19. Jain S, Pathak AC, Kanniyan K, Kulkarni S, Tawar S, et al. (2013) "HighFlexion Posterior-Stabilized Total Knee Prosthesis: Is It Worth the Hype?. " Knee surgery \& related research 25: 100-105.

20. Choong, Peter F, Michelle M Dowsey, and James D. Stoney (2009) "Does accurate anatomical alignment result in better function and quality of life? Comparing conventional and computer-assisted total knee arthroplasty." The Journal of arthroplasty 24: 560-569.

21. Browne JA, Cook C, Hofmann AA, Bolognesi MP (2010) Postoperative morbidity and mortality following total knee arthroplasty with computer navigation. Knee 17: 152-156.

22. Crowninshield RD, Rosenberg AG, Sporer SM (2006) Changing demographics of patients with total joint replacement. Clin Orthop Relat Res 443: 266-272.

23. Fang DM, Ritter MA, Davis KE (2009) Coronal alignment in total knee arthroplasty: just how important is it? J Arthroplasty 24: 39-43.

24. Parratte, Sebastien, Mark W. Pagnano, Robert T. Trousdale, and Daniel J. Berry (2010) "Effect of postoperative mechanical axis alignment on the fifteen-year survival of modern, cemented total knee replacements." The Journal of Bone \& Joint Surgery 92: 2143-2149.

25. Bonner TJ, Eardley WG, Patterson P, Gregg PJ (2011) The effect of postoperative mechanical axis alignment on the survival of primary total knee replacements after a follow-up of 15 years. J Bone Joint Surg Br 93: 1217-1222. 
Citation: Picard F, Clarke J, Deep K, Gregori A (2014) Computer Assisted Knee Replacement Surgery: Is the Movement Mainstream?. Orthopedic Muscul Syst 3: 153. doi:10.4172/2161-0533-3-1000153

Page 6 of 6

26. Longstaff LM, Sloan K, Stamp N, Scaddan M, Beaver R (2009) Good alignment after total knee arthroplasty leads to faster rehabilitation and better function. J Arthroplasty 24: 570-578.

27. Bäthis H, Perlick L, Tingart M, Lüring C, Zurakowski D, et al. (2004) "Alignment in total knee arthroplasty A comparison of computer-assisted surgery with the conventional technique." Journal of Bone \& Joint Surgery, British Volume 86: 682-687.

28. Bauwens K, Matthes G, Wich M, Gebhard F, Hanson B, et al. (2007) Navigated total knee replacement. A meta-analysis. J Bone Joint Surg Am 89: 261-269.

29. Cheng Tao, Song Zhao, Xiaochun Peng, Xianlong Zhang (2012) "Does computer-assisted surgery improve postoperative leg alignment and implant positioning following total knee arthroplasty? A meta-analysis of randomized controlled trials?." Knee Surgery, Sports Traumatology, Arthroscopy 20: 1307-1322.

30. Siston RA, Giori NJ, Goodman SB, Delp SL (2007) Surgical navigation for total knee arthroplasty: a perspective. J Biomech 40: 728-735.

31. Kalairajah Y, Simpson D, Cossey AJ, Verrall GM, Spriggins AJ (2005) "Blood loss after total knee replacement effects of computer-assisted surgery." Journal of Bone \& Joint Surgery, British Volume 87: 1480-1482.

32. Millar NL, Deakin AH, Millar LL, Kinnimonth AW, Picard F (2011) Blood loss following total knee replacement in the morbidly obese: Effects of computer navigation. Knee 18: 108-112.

33. Stöck B, Nogler M, Rosiek R, Fischer M, Krismer M, et al. (2004) "Navigation improves accuracy of rotational alignment in total knee arthroplasty." Clinical orthopaedics and related research 426: 180-186.

34. Siston RA, Patel JJ, Goodman SB, Delp SL, Giori NJ (2005) The variability of femoral rotational alignment in total knee arthroplasty. J Bone Joint Surg Am 87: 2276-2280.

35. Seon JK, Song EK (2006) Navigation-assisted less invasive total knee arthroplasty compared with conventional total knee arthroplasty: a randomized prospective trial. J Arthroplasty 21: 777-782.

36. Lützner J, Günther KP, Kirschner S (2010) "Functional outcome after computer-assisted versus conventional total knee arthroplasty: a randomized controlled study." Knee Surgery, Sports Traumatology, Arthroscopy 18: 1339-1344.

37. Doty B, Zuckerman R, Finlayson S, Jenkins P, Rieb N, et al. (2008) "General surgery at rural hospitals: a national survey of rural hospital administrators." Surgery 143: 599-606.

38. Geddes, George (2006) "Old dogs and new tricks: teaching computer skills to adults." 49-63.

39. Friedberg, Leora (2001) The impact of technological change on older workers: Evidence from data on computer use. No. w8297. National Bureau of Economic Research.
40. Hershatter, Andrea, and Molly Epstein (2010) "Millennials and the world of work: An organization and management perspective." Journal of Business and Psychology 25: 211-223.

41. Small G, Vorgan G (2008) iBrain: surviving the technological alteration of the modern mind New York: Collins.

42. Lüring C, Bäthis H, Tingart M, Perlick L, Grifka J (2006) Computer assistance in total knee replacement - a critical assessment of current health care technology. Comput Aided Surg 11: 77-80.

43. Losina E, Walensky RP, Kessler CL, Emrani PS, Reichmann WM, et al. (2009) "Cost-effectiveness of total knee arthroplasty in the United States: patient risk and hospital volume." Archives of internal medicine 169: 1113.

44. Smith BR, Deakin AH, Baines J, Picard F (2010) Computer navigated total knee arthroplasty: the learning curve. Comput Aided Surg 15: 40-48.

45. Lewis WG, Narayan CV (1993) Design and sizing of ergonomic handles for hand tools. Appl Ergon 24: 351-356.

46. van Veelen Jakimowicz, Kazemier (2004) Improved physical ergonomics of laparoscopic surgery. Minim Invasive Ther Allied Technol 13: 161-166.

47. Berguer R (1998) Surgical technology and the ergonomics of laparoscopic instruments. Surg Endosc 12: 458-462.

48. Fehring TK, Odum SM, Troyer JL, Iorio R, Kurtz SM, et al. (2010) Joint replacement access in 2016: a supply side crisis. J Arthroplasty 25: 1175-1181.

49. Health expenditure, total (\% of GDP)

50. Novak EJ, Silverstein MD, Bozic KJ (2007) The cost-effectiveness of computer-assisted navigation in total knee arthroplasty. J Bone Joint Surg Am 89: 2389-2397.

51. Barbash GI, Glied SA (2010) New technology and health care costs--the case of robot-assisted surgery. N Engl J Med 363: 701-704.

52. Katz JN, Barrett J, Mahomed NN, Baron JA, Wright RJ, et al. (2004) Association between hospital and surgeon procedure volume and the outcomes of total knee replacement. J Bone Joint Surg Am 86-86A: 1909-16.

53. Katz, Jeffrey N, Elena Losina, Jane Barrett, Charlotte B Phillips, et al. (2001) "Association between hospital and surgeon procedure volume and outcomes of total hip replacement in the united states medicare population*." The Journal of Bone \& Joint Surgery 83: 1622-1629.

54. Christensen, Clayton M, Michael E Raynor (2003) The innovator's solution: Creating and sustaining successful growth. Harvard Business Press.

55. Laude F, Moreau P, Vie P (2008) "Arthroplastie totale de hanche par voie ant $\tilde{\odot}$ rieure de Hueter mini-invasive." Maitrise orthop 178. 